Voix et Images

volxetimages

\title{
Montréal et les États-Unis : idéologie et interdiscursivité chez Jean Basile et Réjean Ducharme
}

\section{Jean-François Chassay}

Volume 16, numéro 3 (48), printemps 1991

François Charron

URI : https://id.erudit.org/iderudit/200925ar

DOI : https://doi.org/10.7202/200925ar

Aller au sommaire du numéro

Éditeur(s)

Université du Québec à Montréal

ISSN

0318-9201 (imprimé)

1705-933X (numérique)

Découvrir la revue

Citer cet article

Chassay, J.-F. (1991). Montréal et les États-Unis : idéologie et interdiscursivité chez Jean Basile et Réjean Ducharme. Voix et Images, 16(3), 503-513.

https://doi.org/10.7202/200925ar d'utilisation que vous pouvez consulter en ligne.

https://apropos.erudit.org/fr/usagers/politique-dutilisation/ 


\section{Montréal et les États-Unis: idéologie et interdiscursivité chez Jean Basile et Réjean Ducharme ${ }^{1}$}

\section{par Jean-François Chassay, Université de Montréal}

L'occurrence du mot américanité revient avec insistance dans le discours critique québécois depuis déjà près d'une décennie. Mais, comme l'écrivait Bernard Andrès dans les pages de Voix \& images il y a quelques années, ce terme, comme celui de québécitude, peut renvoyer à un mythe, sans beaucoup de signification 2 .

Il est vrai que depuis le début des années quatre-vingt, on constate que l'occupation de l'espace nord-américain devient une donnée importante de la problématique romanesque, pour s'en tenir à ce genre littéraire uniquement. Nombreux sont les romans ${ }^{3}$ qui se situent en tout ou en partie aux États-Unis. Toutefois, si cette utilisation des lieux géographiques suffit pour parler d'américanité, on peut douter de la solidité du concept.

Pour artificiels qu'ils soient souvent, les nombreux commentaires qu'on peut lire sur l'américanité rendent compte d'un phénomène qui n'a rien de neuf. En réalité, il serait absurde de penser que la réalité américaine ${ }^{4}$ a fait une subite apparition dans le roman québécois au cours des dix dernières années; Guildo Rousseau ${ }^{5}$ a démontré l'importance des États-Unis, de tout temps, dans l'imaginaire des écrivains du Québec. De là à parler d'américanité, il existe un pas qu'il serait un peu. trop simple de franchir. La définition du terme mériterait à elle seule

1 Ce texte va s'intégrer sous une forme partiellement differente dans un chapitre d'un ouvrage collectif du groupe "Montréal imaginaire " de l'Université de Montréal, à paraitre à la fin de l'année 1991, et qui s'intitulera sans doute Montréal à travers les âges. Le chapitre particulier dont il est question ici portera plus précisément sur la présence américaine dans le roman montréalais de 1945 à 1970.

2 Bernard Andrès, "La littérature québécoise à Voix \& images: créneau ou ghetto? „, Voix \& images, 35, hiver 1987, p. 303-312. Voir en particulier p. 310.

3 Notons entre autres les romans de Jacques Poulin, Monique LaRue, Yolande Villemaire, Pierre Turgeon, Jacques Marchand et Madeleine Monette, pour s'en tenir à ceux dont on a le plus parlé.

4 Par américaine, il faudra entendre dans ce texte " états-unienne".

5 Guildo Rousseau, l'Tmage des États-Unis dans la littérature québécoise (1775-1930), Sherbrooke, Naaman, 1981, 356 p. 
une étude sérieuse. La confusion lexicale qui entoure parfois cette notion (de l'américanité à l'américanisme, de l'américanéité en passant par l'américanitude et l'américanophilie ${ }^{6}$ ) indique déjà la difficulté à laquelle on doit faire face si on veut analyser sérieusement ce concept. On peut cependant légitimement souligner, dans un premier temps, limportance de la présence américaine dans le roman québécois.

L'image souvent manichéenne projetée des États-Unis pendant longtemps et que relève Guildo Rousseau - terre de la liberté versus pays sacrilège, matérialiste, protestant, où les gens se vautrent dans le lucre et la luxure - se modifie sensiblement à mesure que l'on approche du milieu du vingtième siècle. À ce moment, le mirage américain, pour reprendre l'expression de Rousseau, commence à s'estomper. La fin de l'émigration des Canadiens français vers les États-Unis, dans les premières années de la Crise, l'alliance provoquée par la Seconde Guerre mondiale signalent déjà des changements. A cela; on peut ajouter des raisons plus littéraires ${ }^{7}$ : dans les années trente, des écrivains regroupés autour d'Alfred DesRochers commencent à défendre l'expression de leur américanité inconditionnelle ${ }^{8}$; Robert Charbonneau, lors du débat qui mènera à la publication de la France et nous, fera scandale par la revendication de l'américanité contre l'Europe et la préférence accordée aux États-Unis, à l'édition américaine contre la française ${ }^{9}$.

Concurremment à cela, l'urbanisation progressive du Québec les citadins représentant la majorité de la population dès $1921^{10}$ va se faire sentir de manière de plus en plus manifeste dans le roman. Or, si cela joue un rôle important dans l'évolution du gen re ${ }^{11}$,

6 Pour plus de détails sur les variations sur ce thème, on pourra consulter l'article de Benoît Melançon, "La littérature québecooise et l'Amérique. Prolégomènes et bibliographie ", Études françaises, vól. XXVI, n² 2 (automne 1990), p. 65-108.

7 À ce sujet, on notera qu'aujourd'hui très peu d'écrivains québécois se réfèrent à la littérature américaine, aussi bien dans leurs textes de fiction que,dans des articles critiques ou des entrevues. On pourrait dire la même chose de la critique en général chez qui la méconnaissance du corpus romanesque américain, contemporain en particulier, est assez manifestc. Dans ce contexte, la notion d'américanité mérite d'autant plus d'être utilisée avec prudence.

8 Robert Vigneault, "La critique littéraire", le Québécois et sa littérature, Sherbrooke, Naaman, 1984 , p. 304.

9 Gilles Marcotte, "Robert Charbonneau, la France, René Garneau ct nous... ", Littérature et circonstances, Montréal, l'Hexagone, 1989, p. 75. Sur cette affaire, on pourra lire également, de Marie Malo, "La France et nous: contexte et histoire d'une querelle", mémoire de maîtrise ès arts, Montréal, Université de Montréal, 1987, IV, 229 f.

10 Voir René Durocher, Paul-André Linteau et Jean-Claude Robert, Histoire du Québec contemporain, tome I, Montréal, Boréal express, 1979, p. 410.

11 Une bibliographie analytique du roman montréalais doit paraftre sous peu à l'Université de Montréal, dans le cadre des travaux du groupe "Montréal imaginaire» (rédigée par Jean-François Chassay, avec la collaboration d'Annick Andrès et Louise Frappier). 
l'importance prise par la culture américaine va être également transformée, indirectement, par ce phénomène.

Dans un texte récent, Raymond Montpetit écrivait que ce n'est pas sous le mode du projet mais bien sous celui plus subtil et silencieux de l'espace, de l'environnement urbain et de la quotidienneté, que l'américanitude est vécue dans la culture du Québec ${ }^{12}$. Dans la mesure où la ville apparaît de plus en plus, pendant cette période qui s'étend sur une vingtaine d'années à partir de la fin des années quarante et que Jean-Claude Marsan nomme l'idéologie de la croissance ${ }^{13}$, comme le lieu du savoir, comme un centre de connaissances et de décisions, où circule l'information, elle est le lieu où peuvent se manifester de la manière la plus convaincante les traces, les signes de la réalité américaine.

On pourrait avancer que dans le roman d'après-guerre, à mesure que la métropole devient un lieu habitable et que la place de Montréal comme lieu physique, topographique, mais aussi comme espace de langage et espace culturel devient importante, la prégnance de la culture américaine se révèle plus forte. Celle-ci se présente de façon moins manichéenne qu'auparavant, cohabite, parfois difficilement - parfois même, pourrait-on dire, convulsivement - avec la culture française. S'identifiant de plus en plus au paysage urbain, le citadin va davantage s'identifier à la culture américaine, acceptant l'importance à la fois de l'une et de l'autre:

Ce passage d'une ville muette, figée et corsetée à une ville foisonnante d'activités, ouverte à tous les discours et affichant clairement son appartenance à la culture américaine - pour le meilleur ou pour le pire - , s'opère au cours du quart de siècle qui suit la guerre et marque manifestement le roman montréalais contemporain, aussi bien que le roman québécois dans son ensemble.

Malgré leurs différences, les textes de Réjean Ducharme (en l'occurrence ici, le Nez qui voque ${ }^{14}$ ) et de Jean Basile (la trilogie composée de la Jument des Mongols, le Grand Khan et les Voyages d'Irkoutsk ${ }^{15}$ ) révèlent cette nouvelle manière d'appréhender la ville, dans les années soixante. Afficher pleinement son appartenance à

12 Raymond Montpetit, «Culture et milieú de vie: l'espace urbain à Montréal ", Écrits du Canada français, 58,1986 , p. 132 . Du même auteur, on pourra également con-sulter * L'autre culture québécoise. La croissance de l'américanité dans la culture québécoise de masse ", Critère, 35, printemps 1983, p. 133-145.

13 Jean-Claude Marsan, Montréal: une esquisse du futur, Montréal, Méridien, 1983 , p. 109.

14 Réjean Ducharme, le Nez qui voque, Paris, Gallimard, 1967, 274 p. Les citations sont tirées de cette édition.

15 Jean Basile, la Jument des Mongols, Montréal, l'Hexagone, 1988, 220 p. (Typo); le Grand Khan, Montréal, l'Hexagone, 1988, 270 p. (Typo); les Voyages d'Irkoutsk, Montréal, HMH, 1970, 169 p. Les citations sont tirées de ces éditions. 
Montréal, c'est également accepter - pour le meilleur ou pour le pire, pour le meilleur et pour le pire - de vivre dans un monde d'abord américain. Vivre à Montréal, pour Ducharme comme pour Basile, c'est vivre dans une ville américaine. Qu'ils habitent Montréal depuis peu, comme les personnages de Ducharme, ne change rien à l'affaire: c'est le fait que la ville soit considérée d'emblée comme américaine qui compte ici. Dans ce contexte, il importe moins d'analyser une représentation imaginaire et littéraire précise que de relever les signes, manifestes ou non, de la présence américaine à travers ces quatre romans, et de voir comment celle-ci se révèle et s'impose à travers le tissu urbain, tant sur les plans idéologique, interdiscursif, qu'intertextuel.

Dans le roman de Ducharme comme dans ceux de Basile, Montréal offre un visage jeune et ceci frappe d'autant plus que les narrateurs des romans en question refusent de vieillir: dans le Nez qui voque, Mille Milles déclare avoir huit ans alors qu'il en a seize et les trois personnages principaux de la trilogie de Basile, qui prendront tour à tour la parole dans chacun des trois romans, refusent de sortir de l'adolescence bien qu'ils abordent la trentaine. Alors que dans les années cinquante, Montréal offrait un visage plutôt sévère à l'instar des protagonistes des romans, prématurément vieillis ou associant, implicitement ou non, l'âge adulte à leurs rêves ou leurs illusions, le roman des années soixante tend davantage à idéaliser l'enfance ou l'adolescence ${ }^{16}$.

Jeunesse, nouveauté, contemporanéité, voilà autant de termes associés spontanément aux Américains. Pourtant, cette réalité ne se présente jamais simplement dans le Nez qui voque de Réjean Ducharme, qui met en scène un adolescent et une adolescente en rupture de ban, et se révèle source de tensions.

La première référence directe à Montréal dans le roman prend place dès la deuxième page et se situe dans le Vieux-Montréal: Ils sont en train de refaire le dôme du marché Bon-Secours. Ils sont en train de restaurer les, lucarnes de la maison Papineau. Ils ont des tâches historiques. Sans accent circonflexe, nous obtiendrons: ils ont des taches historiques (NQV, p. 10). Effectivement, l'Histoire va faire tache dans ce roman, qui commence dans un quartier né avec Montréal et qu'on peut spontanément lier aux origines françaises de la ville.

Cette alliance entre Montréal et la France paraît d'autant plus résistante que le narrateur, dans la même scène, va s'empresser de stigmatiser les Américains:

16 En guise d'exemples, on notera, parmi les romans des années cinquante, la Neige et le feu (Pierre Baillargeon), la Fin des songes (Robert Élie), Évadé de la nuit (André Langevin), Alexandre Chenevert (Gabrielle Roy), Aaron (Yves Thériault), Au milieu la montagne (Roger Viau). 
La chapelle Notre-Dame-de-Bon-Secours recèle un musée de Marguerite Bourgeoys; à côté de l'huis pend une inscription au néon et en anglais: SAILORS' CHURCH 1654. Ils font de la publicité, de l'aplaventrisme, pour mettre l'eau à la bouche des touristes de langue anglaise. Go homme! (NQV, p. 11)

Toutefois Montréal, comme le reste du Canada, se situe bel et bien dans l'orbe américain, pour le meilleur et pour le pire, ce qui complique un peu la situation.

De quoi a-t-il l'air, le Canada, avec la pointe du Maine entrée jusqu'à Saint-Éleuthère, jusqu'au cour, jusqu'à l'eau de la vallée du Saint-Laurent, comme un coin dans une bûche! C'est pire que pire. Qui a vendu la Louisiane, toute la vallée de ce Mississipi que Cavelier de La Salle descendait en canot? (NQV, p.18-19)

La réponse, implicite, nous la connaissons. Napoléon, tout empereur des Français qu'il était, a permis l'américanisation de cet immense territoire et celle-ci s'est propagée jusqu'à Montréal.

À partir de ces balises historiques, la position de Mille Milles, le narrateur, oscillera entre le mépris envers l'Américain et la méfiance envers le Français, l'un servant de repoussoir à l'autre, ce qui permettra, en temps et lieux, de trouver des qualités et à l'un et à l'autre.

Pour Mille Milles, la ville, c'est les hommes qui cherchent à s'enraciner pour toujours. L'homme dépérit, meurt, se couche dans son cercueil et se pulvérise; ses racines de briques restent debout, restent là, à narguer sa tombe [...] (NQV, p. 88-89). Voilà qui peut sembler étrange à première vue, puisqu'on imagine davantage la ville moderne comme un lieu de mouvements, d'effervescence, d'hétérogénéité, de dynamisme. Mais il faut pénétrer la logique du narrateur. La mort, c'est le, réel, le concret. La mort permet d'aller droit au but. Ce qui symbolise le plus et le mieux ce réel (qu'on peut aussi bien définir comme l'âge adulte) s'avère typiquement américain, puisqu'il s'agit de l'automobile et du sexe.

La liberté sexuelle représente non seulement la perte de l'innocence, mais s'oppose diamétralement au plaisir. Le sexe est lié à l'âge adulte et signifie nécessairement le sérieux et la gravité. Le sérieux est d'origine sexuelle, est essentiellement sexuel, augmente avec le désir ou la frustration (NQV, p. 176), dit Mille Milles.

Un des cousins de l'adolescent lui a rapporté une anecdote qui ne laisse pas de doute sur les rapports que les Américains entretiennent avec le sexe:

À cause des homosexuels nombreux [...] sur le boulevard SaintLaurent, tous les homosexuels américains pensent que tous les Canadiens français sont des homosexuels. Mon cousin, qui a fait 
de l'auto-stop aux États-Unis, m'a dit que tous les homosexuels qui l'embarquaient le comptaient de leur bord aussitôt qu'il lui disait qu'il était Canadien français. - Montréal! s’écriaient-ils. [...] Et ils débouclaient leur ceinture de sécurité. (NQV, p. 16)

Le boulevard Saint-Laurent à Montréal évoque cette vie sexuelle débridée qui galvanise les Américains, lesquels, selon Mille Milles, placent sur la couverture de tous leurs livres le mot sexe et une femme déshabillée ou à peu près.

Pas étonnant donc, qu'après une brouille avec Chateaugué, Mille Milles, qui veut se mêler à la faune urbaine pour se changer les idées, se précipite dans un bar sombre du boulevard Saint-Laurent. La scène n'est d'ailleurs pas sans évoquer, sur le mode ironique, le film noir américain. Le matamore qui entre dans ce bar n'a rien d'un héros et ses bravades seraient bien vaines s'il ne se voyait lui-même secouru par Questa, femme flamboyante aux allures holywoodiennes ${ }^{17}$ qui l'entraînera loin de cet antre maléfique voir si la vraie vie est ailleurs. Elle se trouve en tout cas loin de ces amours monnayables, en argent ou en sentiments, dont les Américains, selon Mille Milles, sont passés maitres.

Rien cependant n'est plus avilissant, dégradant et américain que l'automobile: L'homme en automobile est l'homme supérieur que Nietzsche appelait. Hélas, cet homme supérieur est plus supermachine que superhomme. (NQV, p. 12) Les automobilistes imbéciles qui klaxonnent effrontément pour effarer les passants, qui lancent des grivoiseries à la ronde pour insulter les cyclistes, qui rêvent de graver les représentants de la race canine dans les murs de briques, voilà bien ce qu'il y a de plus détestable. Et y a-t-il quelque chose de plus typiquement et de plus vulgairement américain que l'automobiliste sans foi ni loi au volant, justement; d'une "grosse américaine"? Certainement pas: l'un s'associe si bien à l'autre que Mille Milles confond les noms des présidents américains avec ceux de marques de voiture: Ouach! Ouachington! Jefferson! Lincoln! Buick! De Soto! Chevrolet! Plymouth! En avant, maman! (NQV, p. 133)

Ainsi donc, la civilisation américaine imprègne tout le tissu urbain montréalais. Le sexe et la voiture en sont deux symptômes quasi pathétiques. Faudrait-il donc rejeter la civilisation américaine? Les choses ne sont pas si simples. Mille Milles a beau détester son nom, il le préfêre néanmoins à celui de Mille Kilomètres, parce qu'il vénère le système impérial adopté par les Américains. Montréal est à ce point marquée par la culture américaine qu'elle est américaine. $A u$ Canada, même les Esquimaux vivent en Américains (NQV, p. 122),

17 Questa préfigure La Toune, personnage éminemment important de l'Hliver de force, qui paraîtra en 1973. 
déclare-t-il. Il n'y a pas un seul Canadien au Canada. [...] Qui, au Canada, n'est pas de la race des hot-dogs, des hamburgers, du bar-b-q, [...] des buildings, des stops, du Reader's Digest, de Life, de la Metro-Goldwyn-Mayer [...] de Popeye, de Woody the Woodpecker [...] (NQV, p. 122), etc. Refuser de le voir, refuser de le croire, serait au mieux du snobisme, au pire de la bêtise:

Il y en a qui essaient très fort de devenir Canadiens, des durs à américaniser; ils fument des Gitanes, lisent l'Express, pilotent des Citroën [...] et emploient le mot con. Ceux-là, je les hais. Que je hais ces Français manqués, ces espèces de pyromaniaques qui ont honte d'être nés sur ces rives. (NQV, p. 123)

La réaction de Mille Milles est telle qu'il va jusqu'à répondre en anglais à un cinéaste français qui s'adresse à lui.

Faudrait-il donc honnir la France sous prétexte que nous vivons en terre américaine (et, culturellement, en terre états-unienne)? Encore là, les choses ne sont pas si simples. À l'exception du poète Émile Nelligan, les références littéraires de Mille Milles et Chateaugué, qui lisent beaucoup, sont exclusivement françaises. Rimbaud d'abord mais également Colettê, Gautier, Pascal, Molière sont régulièrement appelés à la rescousse. Rodrigue, as-tu du cour? demande Questa à Mille Milles qui, à défaut de Chimène à proximité, avoue se retrouver seul avec [s]es chimères (NQV, p. 155). Baignant dans la culture américaine, Mille Milles rêve et fantasme grâce à la littérature française. Le seul écrivain américain mentionné dans le roman est Henry Miller qui, comme par hasard, a vécu longtemps en France et fut d'abord édité à Paris.

Si la culture française et la culture américaine sont sans cesse confrontées, c'est qu'elles apparaissent manifestement irréconciliables à Mille Milles. Le seul moment où elles sont rapprochées tient du plus pur burlesque. Alors qu'une pièce musicale joue à la radio, Questa déclare que c'est $d u$ jazz [...]. C'est du Jean Racine. C'est le quintette de Vauvenargues (NQV, p. 150). On ne pourrait démontrer plus clairement le fossé qui les sépare.

Dans ces conditions, que reste-t-il à faire, face à deux cultures aussi puissantes? La réponse de Mille Milles est d'une simplicité (faussement) enfantine. Restons où nous sommes. N'avançons pas d'un seul pàs. Restons fidèles. Souvenons-nous. Le temps passe: restons. (NQV, p. 29) Bref, soyons nous-mêmes. Toutefois, dans cet univers de communications et de médiations qu'est devenu le monde urbain, et dont Montréal est ici un bon exemple, être soi, c'est également être sans cesse à l'écoute des autres, ce que le Nez qui voque ne se lasse pas de démontrer.

Aux tensions entre les cultures révélées dans le roman de Ducharme, Jean Basile va répondre par une immersion de plus en plus importante dans la culture américaine au cours de sa trilogie. 
La Jument des Mongols, le Grand Khan et les Voyages d'Irkoutsk mettent' en scène un trio composé de Jérémie, Jonathan et Judith - les trois $\mathrm{J}-$, trois intellectuels ou artistes, plus ou moins ratés, plus ou moins bohèmes, à la dérive dans la ville, cherchant avec un certain désespoir non exempt de dandysme à se raccrocher à une jeunesse qui commence peu à peu à partir en lambeaux.

De façon plus marquée que Ducharme, Basile souligne les joies de la vie en milieu urbain. Montréal devient un phénomène de société positif: des êtres peuvent s'y épanouir. Bassin culturel au sens large, lieu où passent l'information et le savoir, la ville devient un protagoniste essentiel de la diégèse romanesque. Montréal n'est-elle pas ce grand corps qui reste (JM, p. 160)? Corps parfois malade, dégoûtant, purulent, scatologique, mais toujours bien vivant malgré tout ${ }^{18}$.

Les trois $\mathrm{J}$ ne se posent pas de questions sur leur appartenance à cette ville. C'est un monde qu'ils habitent et qui les habite. Leur imaginaire est façonné par la vie montréalaise et leurs allées et venues aussi bien que leurs façons d'être, d'agir, de se vêtir, de manger ou de boire sont indissociables de la vie urbaine. Le lecteur se trouve alors à mille lieux des angoisses d'Alexandre Chenevert par exemple, personnage éponyme d'un roman de Gabrielle Roy, pur citadin qui, quinze ans auparavant, écrasé par la vie urbaine, se sentait toujours comme un invité indésirable dans sa propre ville.

Or, cette ville, qui se présente d'abord et avant tout comme une ville authentiquement nord-américaine, laisse de plus en plus de place à la culture et à la réalité américaines au fil des pages et des volumes. Montréal, où on vit ou croit vivre comme à San Francisco (GK, p. 51), où certains quartiers meurent comme cela s'est sans doute produit dans les villages français de la Nouvelle-Orléans (GK, p. 53), où les choses se passent si souvent comme à New York (GK, p. 204-205), ressemble parfois à s'y méprendre à toutes ces grandes villes américaines qu'on pourrait qualifier de Disneyland pour adultes (GK, p. 85).

De la Jument des Mongols au Grand Khan puis aux Voyages d'Irkoutsk, l'espace occupé par l'actualité politique et culturelle américaine augmente de façon exponentielle. Peu à peu, la présence américaine s'impose tout naturellement dans le paysage montréalais, comme si cela allait de soi. De la guerre du Vietnam à la contreculture, de William Burroughs à Ernest Hemingway, les signes

18 Voir cette scène particulièrement explicite dans le Grand Khan: [...] inventons un fabuleux mélange et comparons: Montréal à un étron, le Saint-Laurent comme une cataracte de pisse, Outremont comme des aisselles puantes, Ville Mont-Royal comme des pieds malodorants, Lachine des crottes de nez, Verdun la cire des oreilles, le pet de Ville d'Anjou, le rot de Longueuil et le reste; Adélaïde a raison, tout est excrémentiel et moi-même je respire tout cela avec délice. (p. 79) 
culturels américains se greffent de plus en plus nombreux à la trilogie à mesure que celle-ci approche de son terme.

Pourtant, il existe un double mouvement dans la trilogie. À cette contemporanéité très américaine répond une mythification des lieux urbains qui propulse Montréal aux sources de la culture, aussi bien orientale qu'occidentale. La Main [le boulevard Saint-Laurent], lit-on dans la Jument des Mongols, c'est notre dimension tragique, la fameuse dimension tragique de ce vieil imbécile d'Eschyle (JM, p. 26). Un quelconque casse-croûte se voit qualifier de mërovingien (JM, p. 25), les graffitis dans les W.-C. d'un autre permettent d'évoquer un tombeau égyptien orné d'hiéroglyphes et de bas-reliefs (JM, p. 25) et si Montréal ne rappelle ni Babylone ni les ruines carthaginoises, le narrateur y décèle un peu Athènes (JM, p. 26). Imaginons, pourquoi pas, au cœur de la ville, un forum pour Héliogabale (GK, p. 259), puisque pour qui le veut, tout est Afrique [...] ou Bagdad (GK, p. 259). Voilà même Montréal propulsée ville des Mille et Une Nuits (GK, p. 258).

N'en doutons pas, il y a là beaucoup d'ironie. Cette mythification et cette symbolisation de la ville peuvent toutefois être utilisées à rebours et connoter les États-Unis si on les met en relation avec ce qui se révèle peut-être l'élément essentiel de la trilogie des Mongols: une quête des origines qui renvoie intertextuellement à Herman Melville et plus particulièrement à Moby Dick.

Il y a un personnage important dans la trilogie, maintes fois cité mais jamais aperçu, sauf dans les dernières pages des Voyages d'Irkoutsk, alors qu'il est mort. Il se nomme Victor, un artistepeintre qui, pendant longtemps, fut la conscience du trio, lorsque ses membres étaient adolescents. Il modèle leurs actions et c'est à travers lui que les trois $\mathbf{J}$ se définissent et marquent l'écart qui les sépare des autres. Jonathan dira à Judith, parlant d'un autre personnage: il n'a pas connu Victor dont nous sommes entre la caricature et l'image (GK, p. 130). Or, Victor, grand amateur de Moby Dick cette affirmation revient à quelques reprises - voyage en mer, à travers le monde, comme le fit pendant des années Herman Melville.

Combien de marins, combien de capitaines, combien de cétacés naviguent ou flottent en ces pages? Le décompte seráit laborieux. Certes, Montréal est une île, mais si on fait souvent mention de son insularité dans le roman montréalais, il est rare que la présence du port ou les allusions aux voyages en mer se fassent si nombreuses.

Vers le milieu de la Jument des Mongols, Billy Budd et Moby Dick font une première apparition par le biais de leur présence dans la bibliothèque de Jérémie. Lidentification aux personnages de ces deux romans, et particulièrement du second, sera telle qu'elle transcendera rapidement le livre. Jérémie glissant comme on imagine que l'est une 
baleine (GK, p. 86), n'est-il pas, malgré tout, un beau marin comme Billy Budd et Jemmy Legs (GK, p. 27) se demande Jonathan, qui imagine très bien Judith en personnage de Melville, sombre marin, Billy Budd, peut-être Achab enfant, Starbuck, Stubb, Flash, sur le Pequod ou le Rachel à la voilure passionnée et sur l'océan brun aux lames glissantes (GK, p. 250). Cette même Judith surgissant des flots comme Moby Dick pour [...] avaler (GK, p. 251) son amant... Jonathan, lui-même écrivain, pourtant long et maigre, se voit avec une gueule de baleine (GK, p.41) et soufflant comme une baleine (GK, p. 231) après l'amour.

Dans le Grand Khan, les personnages de Basile sont identifiés à ceux des romans de Melville. La présence melvillienne prendra des proportions beaucoup plus considérables dans les Voyages d'Irkoutsk. Voilà que Billy Budd est partout (VI, p. 41), à l'image de Dieu d'ailleurs qui, comme chacun le sait, se trouve même dans les voyages de Melville (VI, p. 120). Quoi que nous fassions, nous nous retrouvons toujours dans la grande nuit de Melville à la recherche de son cétacé blanc dans des rêves de gabier de misainè bleu marine (VI, p. 152). Et la présence de Victor se fait sentir, de plus en plus forte au fil des pages. À l'image d'Ismaël, il semble écouter, observer, juger, et même témoigner à travers Jérémie, Jonathan et Judith (ne s'exclament-ils pas toujours Victor disait que...?)

Ces quelques exemples ne forment qu'un relevé fort parcellaire des allusions directes ou indirectes faites à Moby Dick et à son illustre créateur. La présence de plus en plus forte des États-Unis d'un volume à l'autre, essentiellement par le biais de l'actualité politique et culturelle, se conjugue avec une accentuation très nette des signes de l'univers melvillien. La présence de Moby Dick; symbole par excellence du grand roman américain, aux vastes dimensions, confère à la trilogie une dimension épique. Cette épopée des années soixante qui joue sur et à partir de mythes se mire dans les romans d'un écrivain américain lui-même mythifié, créateur d'une œuvre fondatrice et épique. Le sentiment d'appartenance très nette à Montréal dans la Trilogie des Mongols passe par une présence de plus en plus forte de la culture américaine, celle-ci étant marquée par une tension entre l'actualité la plus proche et les mythes fondateurs.

Dans un article publié il y a quelques années, Richard Jones écrivait ce qui suit concernant les rapports entre le Canada - particulièrement le Québec - et les États-Unis:

In the course of the years 1920-1945, the fear of the United States intensified and spread to include at least the most nationalist portion of the elite. After the Second World war, however, traditional fears began to fade away and only a small number of intellectuals continued to fret. Their numbers did increase during the 1960s when the international image of the United States was being ternished by the war in Vietnam, 
internal disorders, and the growth of violent crime. But during this period, the most vibrant Canadian critics of America were to be found in English Canada, particularly Ontario, not in French Canada. Perhaps the "specter" of American civilization was no longer being denounced because Canada had already adopted the major traits of that civilization. The "specter" had become reality. 19

Si cette réalité est acceptée, cela ne veut pas dire qu'elle se vit sans heurts, comme on peut le constater à la lecture de Ducharme et de Basile. Certes, la culture américaine prolifêre à Montréal et, d'une certaine façon, cela fait partie de l'ordre des choses: le monde nordaméricain est urbain, donc américain. Pourtant, une culture prédominante qui se trouve à proximité et qui marque profondément le mode de vie montréalais ne se voit pas consommée passivement dans les romans dont il a été ici question. En ce sens, parler d'une simple américanisation serait un peu court. Ce n'est pas un hasard si les deux auteurs donnent une perspective historique à leurs romans l'un à travers l'histoire politique, l'autre à travers l'hịstoire littéraire. Que cela se fasse sur le mode ludique - parce que cette histoire, justement, n'est pas encore jouée - ne change rien à l'affaire: ce n'est qu'en se resituant dans l'Histoire que Montréal peut acquérir son originalité, ce qui pourrait vouloir dire, en se situant sur un plan territorial, sa propre américanité.

Utilisant un mode de pensée courant dans la culture québécoise, celui du ni-ni — ni Français ni Américain —, Basile et Ducharme tentent de s'approprier leur propre Amérique, qui s'inventerait à Montréal. Si Mille Milles et Châteaugué, Jérémie, Jonathan et Judith, mènent une vie compliquée, la quête existentielle n'étant jamais de tout repos, c'est d'abord parce que cela se déroule dans un univers urbain technologique où l'aventure ne peut plus être ce qu'elle était. Le Far West n'offre plus rien de nouveau aux gens à la recherche de nouveaux territoires. Mais s'il n'y a plus de place pour la découverte, tout est encore à inventer.

19 Richard A. Jones, "French Canada and the American Peril in the Twentieth Century", The American Review of Canadian Studies, vol. XIV, $n^{\circ} 3$, automne 1984, p. 335. Traduction: De 1920 à 1945, la crainte des Etats-Unis s'est intensifíe et s'est étendue à la portion la plus nationaliste de l'élite. Après la Seconde Guerre mondiale, cependant, les craintes traditionnelles commencèrent à s'atténuer et seuls quelques intellectuels continuèrent à se méfier. Leur nombre augmenta durant les années soixante au moment où l'image internationale des Etats-Unis fut ternie par la guerre du Vietnam, les désordres intérieurs et la recrudescence des crimes violents. Mais durant cette période, les critiques canadiennes les plus virulentes à l'endroit des Etats-Unis provenaient du Canada anglais, particulièrement de l'Ontario, et non du Canada français. Si le "spectre" de la civilisation américaine n'était plus dénoncé, c'est peut-être que le Canada en avait déjà adopté les principaux traits. Le "spectre "était devenu réalité. 